\title{
Social Success Factors Affecting Implementation of Agile Software Development Methodologies in Software Industry of Pakistan: An Empirical Study
}

\author{
Muhammad Noman Riaz \\ Department of Computer Science \\ Virtual University of Pakistan \\ Lahore, Pakistan
}

\author{
Athar Mahboob, Attaullah Buriro \\ Department of Electrical Engineering \\ KFUEIT \\ Rahim Yar Khan, Pakistan
}

\begin{abstract}
During the past few years it has been observed that the implementation of Agile software development methodologies have become a part and parcel in software development projects not only in large and developed organizations but also in small organizations despite the existence of misapprehension that Agile methodologies are only valid for large scale projects and established organizations. Keeping in view the potential of Agile software methodologies and with the aim of eliminating this misconception, a mixed method methodology was adopted to conduct a study for determining the social factors that contribute or have influence in the successful implementation of Agile software development methodologies. In this study, face-to-face interview sessions were conducted with 271 software professionals that include Portfolio/Program/Project Managers, Scrum Masters and Product Owners representing 28 software development companies operating in Pakistan to gauge the influence of social factors on the success of Agile software projects. The study concluded that the size of the project has nothing to do with the success of a project or otherwise but there exist certain other factors like visionary leadership, degree or level of Agile software practices, congruence value, etc. contribute significantly in success of a project.
\end{abstract}

Keywords-Agile methodologies; social factors; congruence value; visionary leadership; software developers

\section{INTRODUCTION}

It is a well-established fact that Agile software development methodologies are and applicable and beneficial for the small sized teams and small scaled projects but the implementation and scaling of these Agile methods are daunting and challenging for the software organizations [1][4]. However, contrary to this apprehension large organizations are suffering from the same problems [1]. As the main focus of Agile software development methodologies is the interaction and style of communication among the project team members as well as how the leadership is involved in the planning, execution and monitoring of the project. Furthermore, the main cause of failure of software. development project is not due lack in technological prowess but it is mainly due to social factors such as lack of effective communication among team members at all levels [5], lack of interest in software development, misaligned teams, etc. [6]. So, it is of utmost importance to gain understanding about how and at what extent these social factors contribute and influence in the success of
Agile based projects. Furthermore, the more interest lies in the success or failure of large scale IT projects as these projects are more prone to failures [7]. From research [3], [5], [6] it is evident that social factors like communication barriers, misaligned teams, ineffective leadership must be scaled up to a desired level before implementation of Agile methodologies in both large and small scale projects.

During the study, the factors like communication among team members and factors pertaining to leadership were assessed with respect to their contribution in the success of Agile based software project. Also, the greater emphasis was paid on impact and influence of these social factors on complex 1 and large scale software projects. Finally a conceptual model was proposed based on qualitative interview sessions based on best proven practices and literature. Afterwards, each considered success factor in the proposed conceptual model was assessed and tested in order to determine the relative significance of success factor in the success of Agile based software project.

\section{PROBlem Statement AND RELEVANCE}

The objective of this is to determine the influence of social factors in the success of Agile software development methodologies in small and large scale projects. For this purpose we have two objectives: (1) to verify the previously identified social success factors; and (2) to propose and subsequently test and validate several success factors independently and examine their relationship and influence necessary for the success of Agile project. This study is theoretically related with the previous studies in terms of role of communication and leadership style and presents deep insight of how communication management and leadership styles are appropriate in ever changing environments like Agile Software Development Projects. Secondly, the research gap that exists between social success factors and Agile based software development is likely to be reduced. Also, the results of the study would assist the Agile practitioners in the improvement of communication and leadership practices in the organizations.

\section{THEORETICAL BACKGROUND}

In this study the selection of factors responsible for success in Agile based software projects have been based on the 
preceding research conducted by different researchers in different parts of the world. The prior research works depict that the there are several 'people related factors' that significantly contribute in Agile software development. In this study initially we have considered social success factors like communication style, style of leadership, congruence value, Agile practices adaption degree, and size of the project. The success of the project has been related with the term 'effectiveness' - to what extent and level the project team members have managed to meet or exceed the desired outcomes of quality as demanded by the customer [8] by evaluating multiple points or ratings of success.

The ever changing and at times unrealistic requirements of the organizational leadership are a huge challenge in successful implementation of Agile methodologies especially in large scale projects [3]. A style of leader can evaluated and assessed on the basis of Transactional and Transformational leadership styles [9]. The Transactional leadership style refers to social transactions in which the rewards to the member and expectations that the management has from the team member must be explicitly stated and communicated to the member, and the focus of the management is for a brief period of time. However, as far as the Transformational leadership is concerned it is related with motivation, inspiration, expression of vision and emotional engagement or involvement of employees in the project keeping in view the long term engagement and commitment. It is our expectations that the Transformational leadership is more beneficial than Transactional leadership in Agile software development as the latter put more emphasis on well-being of team members as well encourages healthy communication among the team members at all levels.

From [5] it is evident that the lack of communication among team members of the project creates misunderstandings within the project team that eventually leads to the failure of the project. This lack of communication problem can be catered by encouraging the team members to share their ideas, experiences and knowledge with other members of the project team that helps in trust building and strengthens the interpersonal relationship binding [10]-[12], and these factors are considered as critical success factors for Agile software development [11]. Furthermore, the informal way of communication helps in conveying information without any delay and with the first hand knowledge from the source person to the intended recipient and hence facilitates the decision makers to quickly react on the problem(s) and continuously changing requirements as in Agile software development projects. Therefore, we can say that the style of communication rather than frequency of communication is more critical and important for the success of project and the Agile based software projects are no exception.

In addition how the team members interact with each other and what communication protocol they are following the similarity in values and goals (personal and professional) they possess greatly affects their interpersonal relationships [12], [13]. In case the team members have different values, goals and objectives then diversity occurs in the team and that increases relationship conflicts, decreases level of satisfaction among team members and as a consequence to this the performance of the software development team affected adversely [13], [14]. Therefore, we can say that level of congruence is critical for the alignment of teams and subsequent success of Agile based software project.

Another variable that we have across is the degree of adoption of Agile practices in the organization. This variable indicates perception of agility among project team members. The size of the project refers total number of team members involved in each Agile software project.

\section{RESEARCH STRATEGY}

\section{A. Research Method}

In this research work, the high profile professionals of software industry of Pakistan were identified who have been involved in successful implementation of Agile software development methodologies. The study has been divided in two phases namely: In phase 1, an exploitative phase in which based on the interview sessions with Agile software practitioners a thorough and comprehensive model was developed and phase 2 , in which the developed or proposed model was quantitatively validated.

In Phase 1, an explorative study phase, qualitative interviews were conducted with high profile professionals working in highly reputable software companies of Pakistan and have proven record of successful Agile software development methodologies in large scale projects. During the interview sessions the topics like general aspects of the projects, leadership style and communication pattern practiced during course of the projects. Based on these interview sessions and previously conducted research a comprehensive conceptual model has been developed. The five candidate success factors are: (1) transformational style of leadership; (2) style of communications; (3) congruence value; (4) agility degree; (5) size of project, as shown in Fig. 1 with arrows depicting the interrelationship of each social success factors with one another. Based on the interview sessions we expected that the social success factors other than project size would positively affect the project success. Also, it is expected that style of leadership and style of communication would be meditated with congruence value.

In Phase 2, the aim was to validate the developed conceptual model. The Hypothesis pertaining to relationships between social success factors were tested based on the data collected from 271 software professional that include Professional Scrum Masters, Program and Project Mangers, Product Owners and Team Leads and team members working on 52 different projects and associated with 28 software companies registered with Pakistan Software Export Board (PSEB). To facilitate the study at least one team member, Project / Program Manager, etc. were asked to fill out a questionnaire that permits the comparison of roles in a specific project. An online questionnaire having five sections along with demographic information was distributed to each of the subject / respondent. The included five sections of the questionnaire are: (1) demographic information of the respondent / subject; (2) Agile degree with which organizations are practicing Agile methods; (3) style of leaderships, the style of leadership was evaluated with the help of Multifactor 
Leadership Questionnaire (MLQ) [9]; style of communication; (4) congruence value; and (5) success of project. The respondents responded to questions in each of these sections through 5-Point Likert scale in order to depict the level success perception. The values from all the scales fall within the acceptable reliability limits (Cronbach Alpha), but transactional leadership, and that has been eliminated from the dataset.

Furthermore, in order to determine the contribution of each of the candidate success factors in the project success a Regression and Meditation analyses was carried out at both project and individual level. At project level, a project in which individuals are performing specific roles in cluster was considered as one unit of analysis, thus allows the projects to be compared. At individual level, each respondent was considered as a single unit of analysis and hence allows the comparison of different roles.

\section{B. Ethical Considerations}

This research work has used only the published data and the documents related interview sessions will be made available to public. Therefore, the ethical conflict is not expected to develop.

\section{Research Limitations}

The research in bounded to some limitations as the literature related to Agile software development methodologies as most of Pakistan software companies practicing some software development methodologies rather than using Agile methodologies.

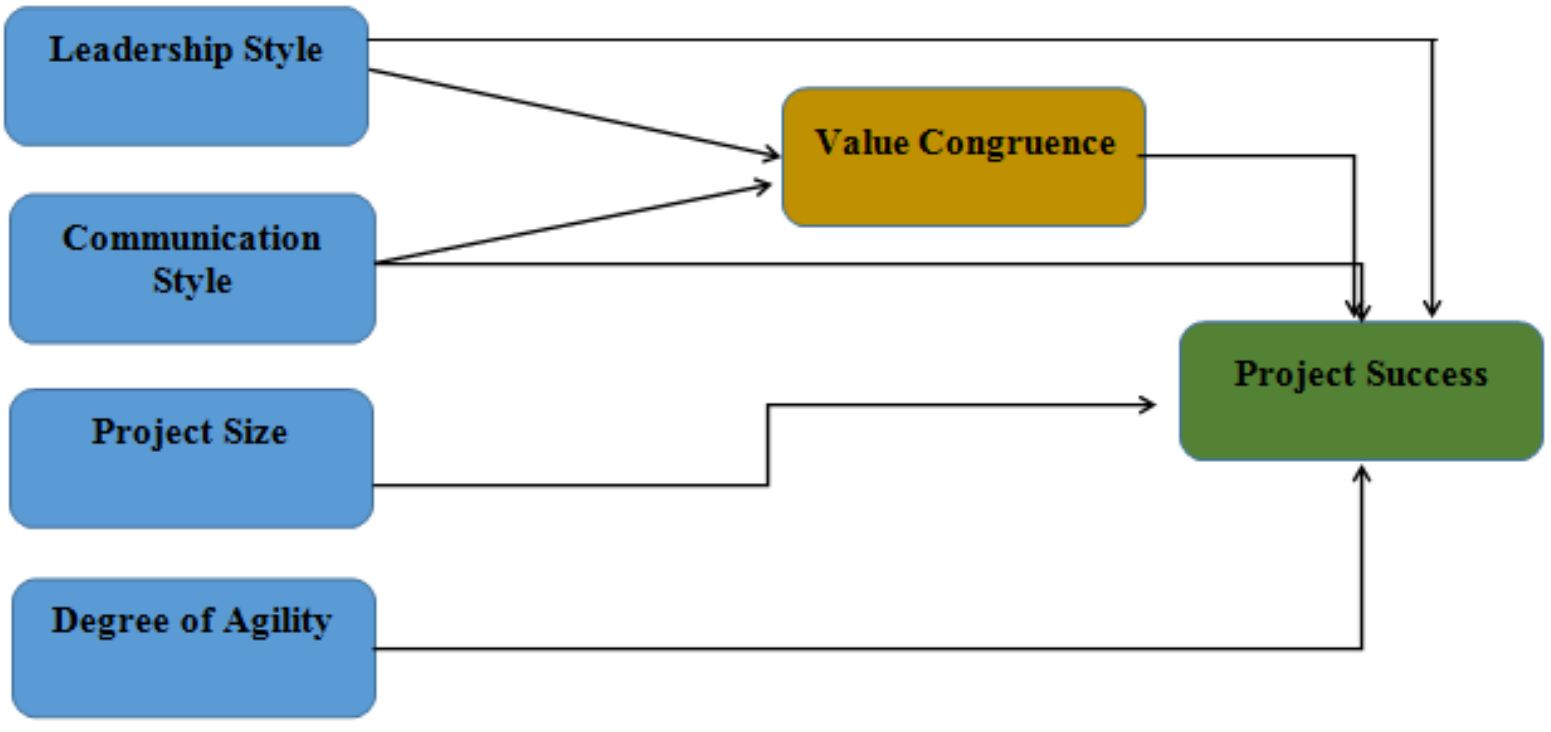

Fig. 1. A conceptual model.

\section{DISCUSSION AND RESULTS}

After collecting the data from the respondents, we carried out T-tests measurement to confirm that there lies no significant difference in the replies of Program / Project Managers, Professional Scrum Masters, Product Owners, project team members, etc. in the interpreting the project success factors. Therefore, in this study the success of project has been interpreted in non - differentiated manner.

Before beginning the testing and validation of developed conceptual model, a Regression Analysis was carried out to determine the relationship between proposed success factors and the success of a project. The analysis results reveal that a significant and positive correlation exists between proposed candidate success factors with the success of a project. However, the size of a project does not reflect any positive correlation with the project success. Furthermore, the results of Regression Analysis depict there exist a predictive relationship between (1) project success and transformational leadership,
(2) project success and value congruence, and (3) project success and degree of agility. Hence, we can say that based on Regression Analysis the most important and critical predictors are transformational leadership, congruence value and degree of Agility in the project.

On the basis of Regression Analysis a Meditation Analysis [14] was carried out when the predictors have a significant relationship with the proposed mediator (value congruence) and the success of project. The results depict that the value congruence was a meditating factor in the proposed conceptual model between value congruence and project success. Furthermore, the results depict that a full mediation was present between transformational leadership and success of project while a partial mediation was observed between degree of agility and project success. Such results clearly show that a high value congruence within the team members, keeping in view that a value congruence is both a mediating and predictor factor as far as the success of project is concerned. 


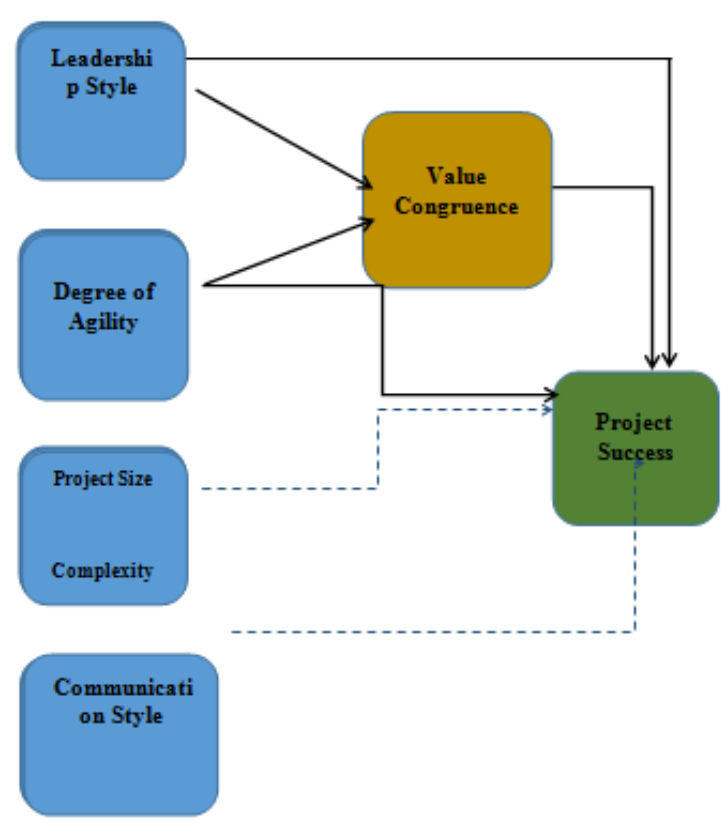

Fig. 2. Revised conceptual model.

The results of Regression Analysis also show that size of the project has nothing to do with the success of the project encouraging the application of Agile methodologies as far as there exist a high degree of transformational leadership, a high degree of agility and a high degree of value congruence.

The results obtained after carrying out such statistical analyses appreciate the refinement of initially developed conceptual model. The findings depict that it is not the style of communication but it is a degree of agility that predicts the success of Agile project, provided it is meditated by value congruence. The revised conceptual model is shown in Fig. 2 in which the significant relationships are depicted by bold arrows.

\section{PRACTICAL IMPLICATIONS}

As from the conducted study we concluded that there exist three critical factors that can have a significant impact on the project success, namely: transformational leadership, degree of agility and value congruence. In order to determine the extent of impact of identified factors on the success of project, the considered projects have been divided into groups. One group is dedicated for the projects that have mediocre score on candidate success factors and other group which scored high on identified success factors. The value congruence and degree of agility have shown a large amount of impact on the project success, 0.50 and 0.45 respectively on Likert-Point scale while transformational leadership scores 0.06 as shown in Fig. 3.

Fig. 4 below depicts the extent to which the three identified success factors affect each other and / or act independently. For this purpose the projects are inspected based on the scores the group of projects scored on project success. The result shows that for project success the scores have been increased monotonously that leads to the fact that all three identified candidate success factors should be given maximum attention to optimize the project success.

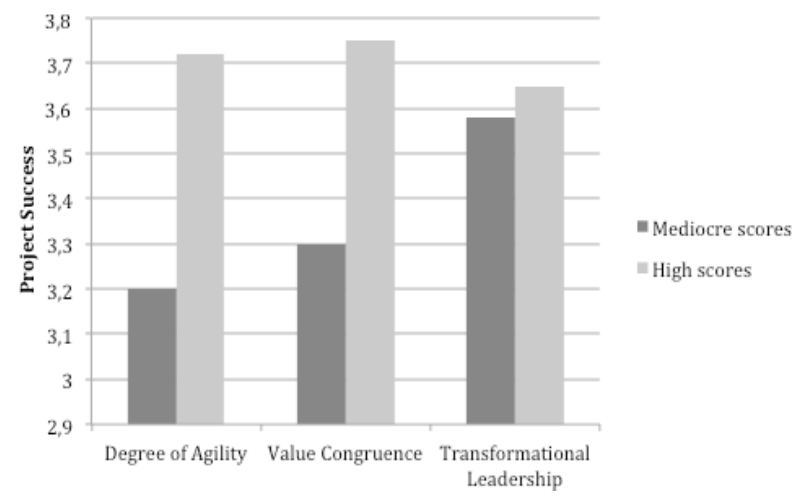

Fig. 3. Critical success factors.

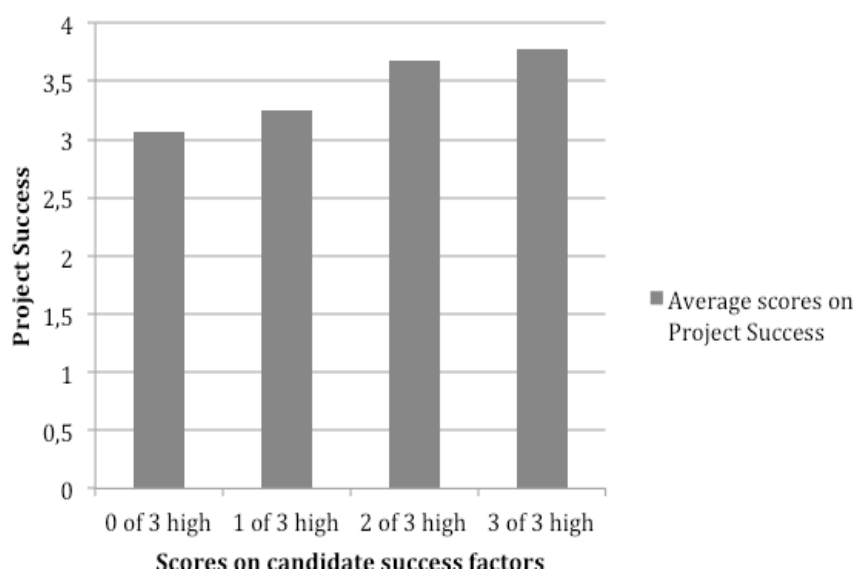

Fig. 4. A trinity of agile project success.

The findings encourage us to focus more on the alignment of values like vision, priorities and organizational goals in Agile projects. The alignment of such values can be achieved by ensuring informal communication among team members on regular basis and maintaining transformational style of leadership [10], [11].

\section{CONCLUSION AND FUTURE RESEARCH WORK}

The study identifies the social factors that may have a profound impact and influence on the success of the project and assessed the role of project size in project success. The study empirically identifies the social success factors based on communication in Agile software development projects by giving an insight of how actually these factors contribute in project success. Furthermore, it has also been revealed from the study that size of the project does not directly contribute in project success or failure. So, the project managers, Scrum masters etc. must focus on the practice of transformational leadership, agility and value congruence.

Furthermore, it is also interesting to note that the Agile methods can work seamlessly in large project however, the Agile puts more stress on short sprints and small teams. It is pertinent to clarify here that the project size does not necessarily have no impact on project success or failure but it is not an explaining factor here. Yes, the large size have more chances to fail as compare to small size projects but this cannot be compulsorily be elaborated by the size of the project. The study clearly reveals that the application of Agile software 
development methodologies can be beneficial for the project when the identified social factors like transformational leadership, value congruence and agile are of high value.

In future, our plan is to increase size and diversity of the sample and study be conducted for a longer period of time in order to further validate the proposed conceptual model.

\section{REFERENCES}

[1] K.Beck, Extreme programming explained: embrace change. Addison Wesley Professional, 2000.

[2] D.J. Reifer, F. Mauer, and H. Erdogmus, "Scaling agile methods," software, IEEE, vol. 20, no. 4, pp. 12-14, 2003.

[3] B. Boehm, "Get ready for agile methods, with care," Computer, vol. 35, no. 1, pp. 64-69, 2002.

[4] J. Eckstein, Agile software development in the large: Diving into the deep. Addison-Wesley, 2013.

[5] M. Bloch, S. Blumberg, and J. Laartz, "Delivering large- scale IT projects on time, on budget, and on value," Harvard Business Review, 2011.

[6] K.A. Jehn, "A multimethod examination of the benefits and detriments of intragroup conflict. Administrative Science Quarterly, vol. 40, no. 2, pp. 256-83, 1995.

[7] J.R. Hackman, The design of work teams. In J. Lorsch (eds.), Prentice Hall, 1987.
[8] B.M. Bass, Leadership and performance beyond expectations, Free Press, 1985.

[9] J.R. Turner, and R. Müller, "Communication and co- operation on projects between the project owner as principal and the project manager as agent," European Management Journal, vol. 22, no. 3, pp. 327-336, 2004.

[10] S. Nerur, R. Mahapatra, and G. Mangalaraj, "Challenges of migrating to agile methodologies, Communications of the ACM, vol. 48 , no. 5, pp. 72-78, 2005.

[11] J.R. Hackman, Groups that work (and those that don't), JosseyBass, 1990.

[12] K.A. Jehn, G.B. Northcraft, and M.A. Neale, "Why differences make a difference: A field study of diversity, conflict and performance in workgroups, Administrative science quarterly, vol. 44, no. 4, pp. 741-763, 1999.

[13] R.M. Baron and D.A. Kenny, "The moderator-mediator variable distinction in social psychological research: Conceptual, strategic and statistical considerations," Journal of Personality and Social Pshycology, vol. 51, pp. 1173-1182, 1986.

[14] R.M. Baron and D.A. Kenny, "The moderator-mediator variable distinction in social psychological research: Conceptual, strategic and statistical considerations," Journal of Personality and Social Pshycology, vol. 51, pp. 1173-1182, 1986. 